\title{
PELATIHAN SURVEI KEPUASAN PELANGGAN UNTUK WIRAUSAHA MUDA
}

\author{
Muhamad Ridwan \\ Seni Kuliner, POLITEKNIK NEGERI MEDIA KREATIF, Indonesia \\ muhamadridwan86@gmail.com
}

\begin{abstract}
ABSTRAK
Abstrak: Tingginya angka pengangguran muda yang mencapai 43,4 persen menjadi titik tolak Rumah Siap Kerja sebagai pusat pelayanan terpadu untuk kegiatan pelatihan keterampilan kerja dan kewirausahaan. Dalam hal membekali para pencari kerja dengan kemampuan untuk berwirausaha dan dapat mengelola usahanya dengan baik. Pelatihan ini bertujuan menyiapkan para pencari kerja yang sudah memulai membuka usaha agar dapat memiliki kemampuan menyursurvei kepuasan pelanggan. Peserta pelatihan adalah masyarakat umum yang tergabung dalam Rumah Siap Kerja selaku mitra pengabdi. Peserta pelatihan berjumlah 15 orang. Setelah mengikuti pelatihan ini peserta akan memiliki kemampuan untuk melakukan survei kepuasan pelanggan secara mandiri. Yang kemudian hasil survei tersebut dapat digunakan peserta yang memiliki usaha untuk keperluan mengidentifikasikan apa yang dibutuhkan dan diinginkan oleh pelanggannya dan berupaya memperkecil perbedaan (gap) apa yang diinginkan dan produk yang dihasilkan dengan apa yang sebenarnya pelanggan terima. Lebih dari 50\% peserta pelatihan ini mengalami peningkatan kemampuan baik secara soft skill maupun hardskill.

Kata kunci: pelatihan, wirausaha, kepuasan pelanggan

Abstract: The high youth unemployment rate which reached 43.4 percent became the starting point for the Ready to Work Home as an integrated service center for job skills training and entrepreneurship activities. In terms of equipping job seekers with the ability to be entrepreneurial and able to manage their business well. This training aims to prepare job seekers who have started a business so that they can have customer satisfaction survey skills. The training participants are the general public who are members of the Ready-to-Work House as a service partner. There were 15 participants in the training. After participating in this training, participants will have the ability to independently conduct customer satisfaction surveys. The results of the survey can then be used by participants who have businesses for the purpose of identifying what their customers need and want and trying to minimize the gap between what they want and the product they produce with what customers actually receive. More than 50\% of the training participants experienced an increase in both soft skills and hard skills.

Keyword: Workshop, Enterpreneur, Customer Satisfaction
\end{abstract}

\section{A. LATAR BELAKANG}

Badan Pusat Statitik (2018) merilis data pengangguran untuk mereka yang berusia 15 - 24 tahun atau yang disebut dengan angkatan muda mencapai 43,4 persen. Rumah Siap Kerja sebagai pusat pelatihan kerja untuk kaum muda hadir sebagai solusi untuk menekan angka pengangguran angkatan muda ini melalui beberapa program seperti pelatihan keterampilan, kewirausahaan, dan beasiswa pendidikan. Sejak dibuka pada beberapa bulan lalu yaitu di bulan April 2019, berbagai pelatihan keterampilan, kewirausahaan, dan beasiswa pendidikan sudah digelar.

Taqiyudin (2010:102) menuliskan, pendidikan berwawasan kewirausahaan yaitu pendidikan yang menerapkan prinsip-prinsip dan metodologi ke arah pembentukan kecakapan hidup (life skill) pada peserta didiknya melalui kurikulum yang terintegrasi yang dikembangkan di sekolah.

Pada dasarnya tujuan utama berwirausaha adalah mencari keuntungan, dalam hal ini adalah laba. Laba dapat diperoleh dari para pelanggan atau konsumen, maka muncullah 
alasan mengapa konsumen memilih barang/jasa tertentu dalam mencapai kepuasan. Pada saat perusahaan dapat menyediakan kebutuhan yang bisa membuat para konsumen merasa puas, maka perusahaan tersebut akan lebih mudah dalam mencapai keuntungan yang diinginkan. Untuk itu agar laba yang diinginkan dapat diperoleh dengan maksimal, maka faktor yang sangat penting dalam bisnis adalah menciptakan dan juga mempertahankan konsumen. Menurut Philip Kotler (1997: 36) kepuasan memiliki makna sebagai berikut: "Kepuasan adalah perasaan senang atau kecewa seseorang yang berasal dari perbandingan kesannya terhadap kinerja (atau hasil) suatu produk dan harapannya.

Untuk dapat mengetahui sejauhmana kebutuhan pelanggan telah terpenuhi dan sejauhmana pelanggan merasakan kepuasan atas produk yang dibelinya, perlu dilakukan analisa kepuasan pelanggan melalui sebuah pengukuran kepuasan pelanggan. Untuk itu, muncullah ide kami mengadakan kegiatan pelatihan survei kepuasan pelanggan untuk wirausaha muda. Pelatihan Survei Kepuasan Pelanggan ini merupakan suatu cara agar seorang wirausaha dapat membaca tingkat kebutuhan, keinginan dan harapan dari pelanggan serta merespon dengan memenuhinya sehingga mengakibatkan terjadinya pembelian ulang atau kesetiaan yang berlanjut.

\section{B. METODE PELAKSANAAN}

Kegiatan pelatihan survey kepuasan pelanggan menggunakan metode pelatihan yang terdiri dari kegiatan presentasi, tanya jawab, simulasi dan praktik membuat kuesioner secara langsung.

Rumah siap kerja digagas oleh Sandiaga Uno sebagai salah satu program kerja pada saat kampanye pemilihan Presiden RI tahun 2019. Berdiri pada 16 Maret 2019, beralamat di J1. Wijaya I No. 26, Jakarta Selatan, DKI Jakarta 12170. Sejak awal berdiri telah mengadakan lebih dari 200 pelatihan profesional. Sejak akhir tahun 2019, Rumah Siap Kerja telah bebas dari afiliasi politik dan kini dipimpin oleh Reostiadi Tsamanov. Rumah Siap Kerja merupakan tempat bagi para anak muda untuk mendapatkan bimbingan karir, mencari informasi lowongan pekerjaan, pelatihan professional dan Pendidikan yang didukung dalam beragam fasilitas bagi anak muda. Pelatihan ini diminati sebanyak 30 peserta yang mendaftar dalam kegiatan.

Pelaksanaan kegiatan pelatihan ini memiliki langkah-langkah sebagai berikut:

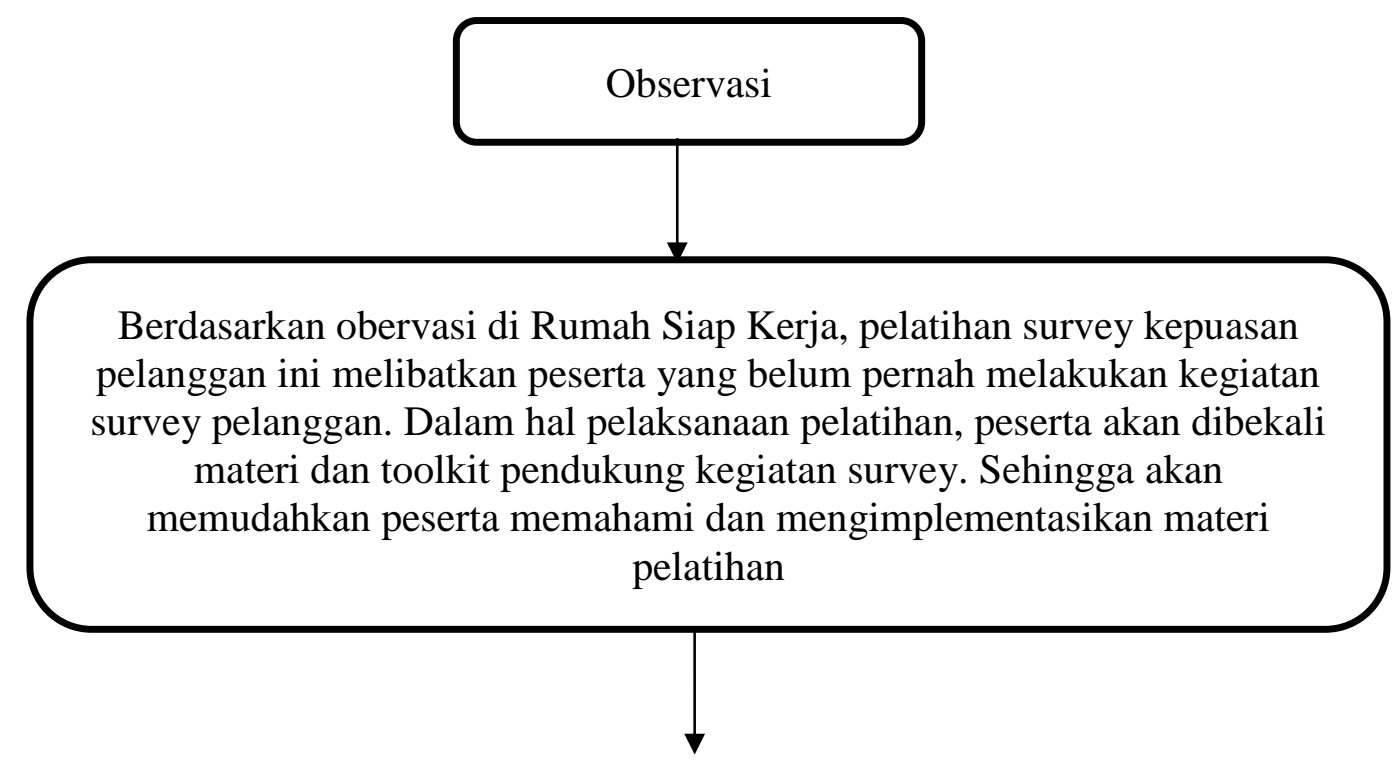


Pelaksanaan Pelatihan : Pelatihan ini mencakup penyampaian materi mengenai tahapan melaksanakan survey kepuasan pelanggan yang meliputi Simulasi

Praktek pembuatan kuesioner, tehnik sampling dan tehnik pengumpulan data. Untuk membantu peserta melaksankan kegiatan tersebut dibantu oleh kuesioner dan seperangkat toolkit untuk sampling dan pengumpulan data dari mulai lembar acak kish grid, lembar acak RT RW, dan lembar acak rumah tangga.

Evaluasi Kegiatan

Gambar 1 langkah-langkah Pelaksanaan kegiatan

1. Observasi langsung

a. Survey tempat pelaksanaan kegiatan

b. Kegiatan pengabdian masyarakat pelatihan survey kepuasan pelangaan bagi wirausaha muda ini diperuntukan untuk wirausahawan muda yang tergabung dalam komunitas Rumah Siap Kerja.

c. Pengabdi membuat materi/modul serta perangkat yang dibutuhkan dalam mempermudah peserta memahami tahapan pelatihan.

d. Jadwal pelatihan disesuaikan dengan agenda di Rumah Siap Kerja yang terlebih dahulu dikoordinasikan dengan pihak panitia.

e. Koordinasi dalam penyediaan perangkat pengabdi menyiapkan materi dan toolkit, peserta membawa laptop untuk simulasi praktek.

2. Pelatihan

a. Pelatihan ini mencakup Pelatihan ini mencakup penyampaian materi mengenai tahapan melaksanakan survey kepuasan pelanggan yang meliputi Simulasi Praktek pembuatan kuesioner, tehnik sampling dan tehnik pengumpulan data. Untuk membantu peserta melaksankan kegiatan tersebut dibantu oleh kuesioner dan seperangkat toolkit untuk sampling dan pengumpulan data dari mulai lembar acak kish grid, lembar acak RT RW, dan lembar acak rumah tangga.

b. Target peserta kegiatan ini adalah 30 orang peserta pelatihan.

c. Fasilitas seperti laptop, monitor dan sound disediakan sesuai kebutuhan oleh pihak panitia dari Rumah Siap Kerja.

3. Evaluasi

Setelah pelatihan berakhir, tentunya perlu adanya evaluasi yang dilakukan untuk melihat sejauh mana perkembangan hasil yang didapatkan dari pelatihan apakah telah berjalan dengan baik atau belum sekaligus evaluasi kekurangan dari pelaksanaan. Selama kegiatan juga dilakukan pengamatan apakah tujuan dan target dari pelaksanaan pelatihan ini sudah tercapai untuk sekaligus membahas tentang kendala-kendala yang mungkin ditemui dalam pelaksanaan. 
66 | PEKAMAS (Pengabdian Kepada Masyarakat) | Vol. 1, No. 2, Desember 2021, hal. 63-69

\section{HASIL DAN PEMBAHASAN}

Kegiatan pengabdian masyarakat pelatihan survey kepuasan pelanggan untuk wirausaha muda di Rumah Siap Kerja dilakukan dengan tahapan sebagai berikut:

1. Pemaparan materi dan simulasi praktik

a) Tahapan pertama pada kegiatan survey kepuasan pelanggan ini adalah pemaparan materi yang meliputi pengertian, maksud dan tujuan, tata cara, dan penjelasan mengenai bagaimana kuosioner dibuat dan tehnik sampling serta pengumpulan data dilakukan.

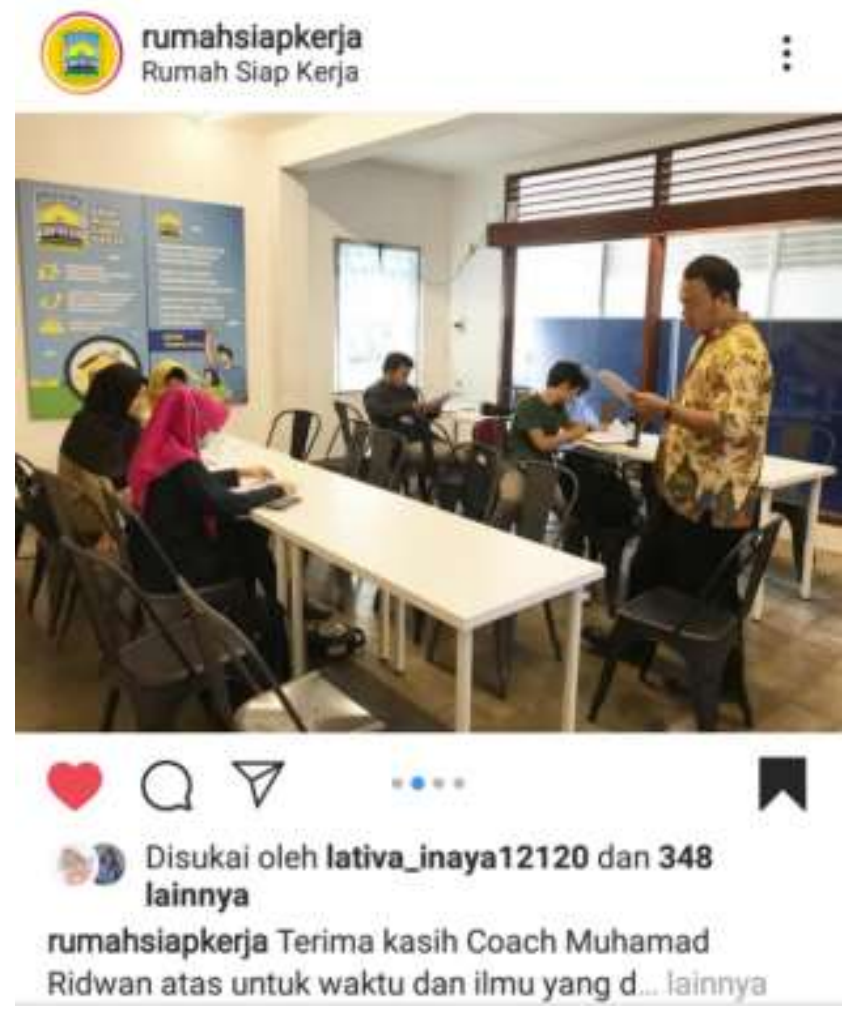

Gambar 2 pemaparan materi 
b) Simulasi praktik pembuatan kuesioner

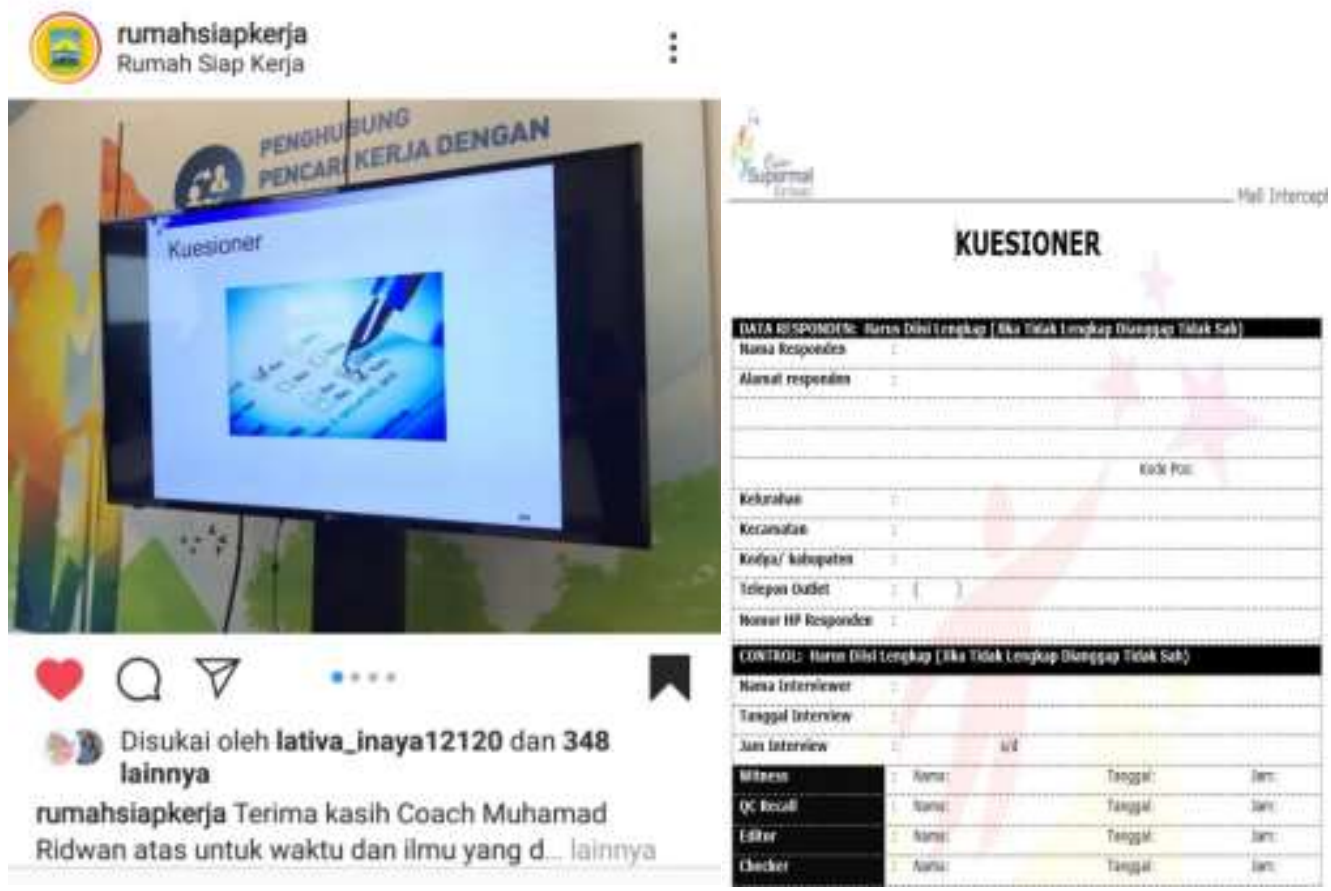

Gambar 3 praktik pembuatan kuesioner

Peserta diberikan materi bagaimana cara membuat kuesioner yang merupakan instrumen dalam kegiatan survey kepuasan pelanggan.

Metode pendekatan dalam kegiatan ini akan lebih banyak ke simulasi. Para peserta hanya mendapatkan $30 \%$ teori yang disampaikan oleh pemateri dengan metode presentasi interaktif. Mayoritas isi kegiatan yaitu 70\% akan berupa praktek dari teori yang sudah dijelaskan melalui simulasi.

c) Simulasi tata cara tehnik sampling

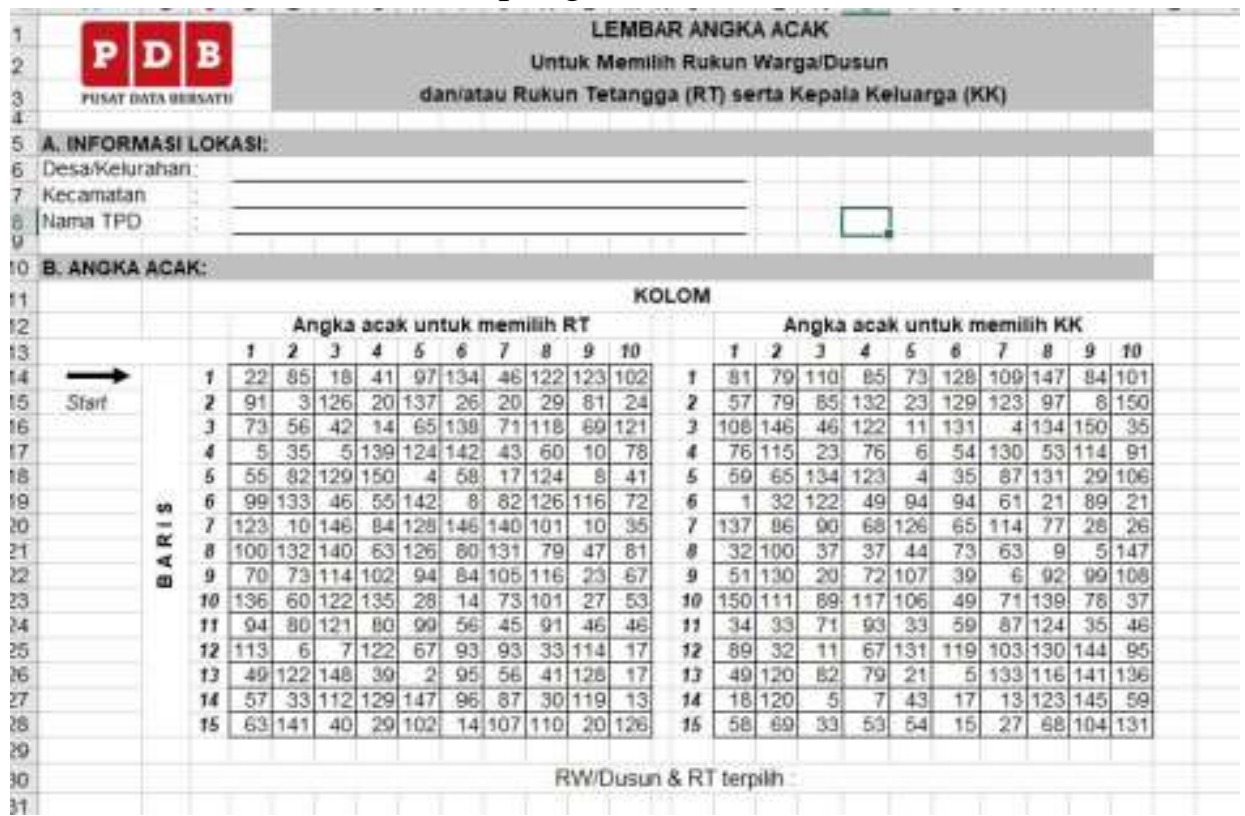

Gambar 4 cara menentukan sampling

Peserta diberikan materi bagaimana cara menentukan sampling untuk kegiatan survey kepuasan pelanggan. 
2. Monitoring dan evaluasi

Monitoring dan Evaluasi kegiatan pengabdian masyarakat ini dilakukan secara langsung simultan dengan pelaksanaan kegiatan. Di setiap sesi pelatihan peserta diminta menjelaskan materi yang sudah didapat, sehingga dapat diketahui bagaimana peningkatan pengetahuan maupun keterampilan peserta setelah mengikuti pelatihan ini. Indicator keberhasilan pelatihan ini didapat dari informasi yang disampaikan oleh peserta yang ditanyai secara verbal oleh pengabdi, lebih dari $70 \%$ peserta merasa sudah meningkat pengetahuan serta kemampuannya dalam hal survey kepuasan pelanggan setelah mengikuti pelatihan survey kepuasan pelanggan.

3. Kendala yang dihadapi

Secara umum tidak terdapat kendala dalam pelaksanaan kegiatan pelatihan survey kepuasan pelanggan ini. Hanya saja agar peserta dapat memahami materi dengan sempurna, diperlukan pelatihan lebih lanjut agar peserta bisa lebih terbiasa lagi melaksanakan semua tahapan kegiatan survey kepuasan pelanggan.

Tabel 1 Agenda Kegiatan

\begin{tabular}{|c|l|l|}
\hline Waktu & \multicolumn{1}{|c|}{ Kegiatan } & Penanggung Jawab \\
\hline $12: 30$ & Registrasi Peserta & Panitia \\
\hline $12: 45$ & Pembukaan dan Ice Breaking & M Ridwan \\
\hline $13: 00$ & $\begin{array}{l}\text { Pemaparan Pendahuluan dan tujuan survei } \\
\text { kepuasan pelanggan }\end{array}$ & M Ridwan \\
\hline $14: 00$ & $\begin{array}{l}\text { Pemaparan Tahapan survei kepuasan } \\
\text { pelanggan }\end{array}$ & M Ridwan \\
\hline $15: 00$ & $\begin{array}{l}\text { Simulasi Praktek pembuatan kuesioner, tehnik } \\
\text { sampling dan tehnik pengumpulan data }\end{array}$ & M Ridwan \\
\hline $16: 00$ & Penutupan dan Evaluasi & M Ridwan \\
\hline
\end{tabular}

\section{SIMPULAN DAN SARAN}

Kegiatan pelatihan survei kepuasan pelanggan ditujukan untuk para wirausaha muda ataupun calon wirausaha agar mereka mampu membuat dan merancang kegiatan survei secara mandiri untuk keperluan pengembangan usahanya. Pada pelatihan ini peserta diberi materi kemampuan membuat survei kepuasan pelanggan. Dengan diadakannya pelatihan ini diharapkan seorang wirausaha dapat dengan tepat mengidentifikasikan apa yang dibutuhkan dan diinginkan oleh pelanggannya dan berupaya memperkecil perbedaan (gap) apa yang diinginkan dan produk yang dihasilkan dengan apa yang sebenarnya pelanggan terima.

\section{UCAPAN TERIMA KASIH}

Penulis mengucapkan terima kasih kepada Pusat Penelitian dan Pengabdian kepada Masyarakat (P3M) Politeknik Negeri Media Kreatif yang telah mendukung kegiatan pelatihan ini sehingga terlaksana dengan baik. Penulis juga mengucapkan terima kasih kepada Rumah Siap Kerja yang telah bersedia memberikan kesempatan untuk melaksanakan pengabdian masyarakat. Semoga kegiatan pengabdian masyarakat ini bisa bermanfaat untuk masyarakat secara luas. 


\section{DAFTAR RUJUKAN}

Sugiyono. (2012). Metode Penelitian Bisnis. Alfabeta. Bandung Sugiyono dan Wibowo, E. (2004). Statistika untuk Penelitian. Alfabeta. Bandung

Suharyadi dan Purwanto. (2016). Statistika untuk Ekonomi dan Keuangan Modern. Edisi 3 Buku 1. Salemba Empat. Jakarta 